Psychological Medicine, 1982, 12, 241-242

Printed in Great Britain

EDITORIAL

\title{
DSM-III and the future orientation of American psychiatry ${ }^{1}$
}

In 1980, the American Psychiatric Association (APA) adopted the Diagnostic and Statistical Manual of Mental Disorders, third edition (DSM-III), as its official classification system. Work on this system had begun six years earlier when the APA appointed the Task Force on Nomenclature and Statistics, under the chairmanship of Robert Spitzer, which then began the intensive review of the scientific literature and the solicitation of input from a large and varied array of clinicians that ultimately was to determine the form and content of DSM-III (Spitzer et al. 1980).

Critical reviews of the success of this enterprise have been mixed to date. In a recent book review in this journal (Psychological Medicine, 1981), DSM-III was referred to as a 'hodgepodge' which contains 'many idiosyncratic features that will be puzzling to non-Americans for whom the 9th Revision of the International Classification of Diseases will continue to remain the yardstick in this field'. Somewhat more positively, an article in the Lancet, entitled 'A reappraisal of American psychiatry', noted: 'The incorporation of operational definitions into the diagnostic manual gives the U.S.A. an everyday classificatory system potentially superior to those in use elsewhere in the world' (Murray, 1979). Such a variation in opinion reflects the fact that numerous mental health practitioners, in the United States as well as abroad, continue to have significant reservations about this new system. This editorial reviews briefly some of those reservations, and examines the possible implications of DSM-III for the future orientation of American psychiatry.

Apart from the intimidating size of the document, which has proven a source of distress to some, there appear to be two major and several minor areas where substantial scientific and philosophical differences arise. Setting aside the minor areas of disagreement, the two major areas of debate concern the concept of schizophrenia and the reshaping of those disorders formerly classified as the neuroses.

Numerous research enterprises, perhaps most notably the US-UK Cross-National Diagnostic Study (Kramer \& Zubin, 1969), have attested to the generosity with which American psychiatrists distributed the diagnosis of schizophrenia in the past. Following in the footsteps of more rigorous evaluative approaches, such as the Research Diagnostic Criteria (Spitzer et al. 1975), DSM-III clearly offers a narrower concept which calls for symptoms of active psychosis, relatively early onset, a chronic or relapsing course, and at least temporary deterioration in functioning. Those critical of this approach argue that it allows the definition of a more homogeneous group that will lead with an overemphasis on chronicity and an inevitably downhill course (Kraepelin, 1918). Supporters of this approach argue that this allows the definition of a more homogeneous group that will lead to more consistent and appropriate treatment (Spitzer et al. 1978). They also point out that this will substantially narrow the gap between American and European concepts of schizophrenia, and thus lead to more productive international research.

More alarming to many diagnosticians is the 'dismantling' (Hyler \& Spitzer, 1978) of the neuroses in DSM-III. The psychoanalytical framework of theory on which these disorders were based and grouped together has apparently been abandoned in DSM-III, which instead distributes these disorders according to their principal symptoms or other descriptive features. It might be noted that DSM-III explicitly endorses unconscious conflict leading to symptom formation as the aetiological explanation for conversion disorder. Further, DSM-III continues to endorse the term 'neurotic' as descriptively useful in depicting patterns of behaviour that are characterized by non-psychotic impairment. Philosophical and political as well as scientific considerations continue to be apparent

\footnotetext{
1 Address for correspondence: Dr Murray Morphy, Mental Health Clinic, Veterans Administration Medical Center, 3495 Bailey Avenue, Buffalo, NY 14215, USA.
} 
in this debate, whose outcome is as yet uncertain. The ICD-10 and/or DSM-IV may reflect some resolution of these two highly divergent diagnostic strategies. The DSM-III approach to this group of disorders will certainly need to demonstrate superior clinical utility before any impact on the international classification system is likely.

\section{FUTURE ORIENTATION OF AMERICAN PSYCHIATRY}

Psychiatry in the United States, as elsewhere, has often been estranged from the remainder of the medical community. Various explanations have been offered for this, most prominently the influence of psychoanalysis and the long-standing and quite deliberate isolation of psychiatric hospitals (Shepherd, 1957). The role blurring among mental health professionals that was particularly common in the United States' version of community psychiatry added further to American psychiatry's problems of identity diffusion. 'Riding off madly in all directions' (Grinker, 1964) was an apt description of American psychiatry in the 1960s and early 1970s.

With support from the medical community decreasing, and conflict with mental health colleagues increasing, it is perhaps not surprising that American psychiatry might sense a need for a change in orientation. In timely fashion, the rapidly expanding knowledge in such areas as neurophysiology and psychopharmacology made 'remedicalization' of the field a rather obvious and desirable choice for such a reorientation. DSM-III is important in this reaffirmation of the psychiatrist's unique capabilities as a specialist in behavioural medicine. While recognizing the remaining deficiencies in our knowledge, it does incorporate many of the recent gains made in our understanding of mental illness and stands as a landmark, albeit a somewhat flawed one, in psychiatry's scientific maturation. The focus on detailed behavioural descriptions in DSM-III does not compensate, however, for the extensive ignorance that persists regarding the aetiology of most psychiatric disorders. A potential danger is that DSM-III utilizes elaborate diagnostic criteria and other admirable features that may disguise our ignorance far more than is scientifically healthy.

As to the future orientation of American psychiatry, it is unlikely that any single viewpoint or value system will, or should, gain ascendancy in a field so broad and varied. The issues are not as clear as DSM-III sometimes seems to suggest. Psychiatrists will continue to involve themselves in many different types of practice in a wide variety of settings. Stimulating differences in theoretical orientation will continue. Nevertheless, an increasing scientific consensus as the basic knowledge of the field expands makes a greater sense of shared identity possible.

It is the position of this editorial that DSM-III reflects progress in moving towards a scientific consensus, and that its successors will do so to an even greater degree. Further, it appears that DSM-III and the consensus it reflects is emerging as a major factor promoting the rising affinity of American psychiatry for a genuine medical identity, an identity which perhaps was never 'lost' by European medical colleagues. This need not be a retreat to the security of the white coat, but instead it could lead to a renewed emphasis on rigorous research and analysis. No abandonment of the consistent effort to increase the compassion and empathy with which the mentally ill and emotionally disturbed are treated is implied. Art and science are hopefully as compatible in psychiatry as elsewhere in medicine. The biopsychosocial complexity of the patients we serve demands that we derive the best we can from both our finest artistry and our most exacting science.

MURRAY A. MORPHY

\section{REFERENCES}

American Psychiatric Association (1980). Diagnostic and Statistical Manual of Mental Disorders (DSM-III). APA: Washington, D.C.

Grinker, R. R. Sr (1964). Psychiatry rides madly in all directions. Archives of General Psychiatry 10, 228-237.

Hyler, S. E. \& Spitzer, R. L. (1978). Hysteria split asunder. American Journal of Psychiatry 135, 1500-1504.

Kraepelin, E. (1918). Dementia Praecox. E. and S. Livingstone: London.

Kramer, M. \& Zubin, J. (1969). Cross-National Study of Diagnosis of the Mental Disorders. American Journal of Psychiatry 125, Supplement, 1-46.

Murray, R. M. (1979). A reappraisal of American psychiatry. Lancet https://doi.org/10. 1025500238291700046560 Published online by Cambridge University Press
Psychological Medicine (1981). Book review: DSM-III; 11, 215.

Shepherd, M. (1957). An English view of American psychiatry. American Journal of Psychiatry 134, 4l 7-420.

Spitzer, R. L., Endicott, J. \& Robins, E. (1975). Research Diagnostic Criteria (RDC) for a Selected Group of Functional Disorders (2nd edn). Biometrics Research: New York.

Spitzer, R. L., Anderson, N. \& Endicott, J. (1978). Schizophrenia and other psychotic disorders in DSM-III. Schizophrenia Bulletin 4, 489-509.

Spitzer, R. L., Williams, J. B. W. \& Skodol, A. E. (1980). DSM-III: The major achievements and an overview. American Journal of Psychiatry 137, 151-164. 